\title{
Chemical and Biological Studies on the Formulation of Antibiotics and Organic Mercurial Compounds
}

\author{
Part I. Investigation on Compatibility of Blastcidin $\mathbf{S}$ and \\ Phenylmercuric Acetate \\ By Yoshio IsHII \\ Institute of Agricultural Chemicals, Toa Noyaku Co., Ltd., Odawara \\ Received September 20, 1961
}

\begin{abstract}
During the course of investigation on the formulation of Blastcidin S and PMA, it was found that some types of surface active agents and lignin sulfate gave undesirable influences to Blastcidin S, while lignin sulfate had a bad effect upon PMA.
\end{abstract}

The effect of Blastcidin S against rice blast disease, Piricularia oryzae, has been already confirmed and put into practical use. Blastcidin $S^{1)}$ is stable against ultra-violet rays and also at wide $\mathrm{pH}$-range. Blastcidin $\mathrm{S}$ not only has the stronger therapeutic effect than that of PMA (phenylmercuric acetate) at the same concentration but also has the characteristic protective value among the usual antibiotics. Nevertheless it does not have a residual effect like PMA so that it is defective compared with PMA in the protective effect at the same concentration (converted into $\mathrm{Hg}$ content). Accordingly, if Blastcidin S and PMA were mixed and sprayed, it is considered that this mixture should have both therapeutic and protective effects. Still more, the synergistic or co-operative action can be expected with antibiotics and mercuric compounds. These are the main reasons why they are tested in the form of mixing compound. But, as there are various types of formulated substances, it is desirable to apply with the formulated type of fixed concentra-

1) Yonehara et al, J, Antibiotics, Ser. A, 11, 254 (1958). tion rate. Then, investigations were carried out on formulations of two substances, and biological tests were performed on each formulation. Blastcidin $\mathrm{S}$ is supposed to be unstable in alkaline solution, but when Blastcidin $\mathbf{S}$ is mixed with alkaline carrier, the situation is different because in this case the reaction proceeds heterogeneously.

To carry out the test promptly the stability of Blastcidin $\mathrm{S}$ was investigated under severe conditions (at the temperature of $60^{\circ} \mathrm{C}$ for 3 weeks). The same tests were carried out on PMA. In the case of PMA, however, it is so stable in alkali than PMA is generally used with slaked lime for controlling rice blast disease.

The stability was judged by adding alone various surface active agents to the aqueous solution of PMA keeping in thermostat $\left(40^{\circ} \mathrm{C}\right)$ for 3 to 6 days and measuring the degradation rate of PMA by the surface active agent.

As an analytical method, dithizone-colorimetric methods was adopted instead of dithizone titration method by considering the 
influence of surface active agent. Tests above mentioned were carried out to investigate the characteristics of wettable powder or dust formulation of Blastcidin S, because Blastcidin $S$ is soluble in water and insoluble in most organic solvents.

\section{EXPERIMENTAL}

1) The Stability of Blastcidin S Under Severe Conditions.

The mixing ratio of sample and Blastcidin $\mathrm{S}$ is $1: 1$ (wt/wt) and the potency of Blastcidin $S$ was determined by bioassay. The testing organism is Bacillus cereus IAM 1,729. The mixed substances are introduced into glass bottles $\left(60^{\circ} \mathrm{C}\right)$ and sampled on 9 th day. The determination is repeated twice, and the average values are shown in Table $I$.

2) The Decomposition Test of PMA at $45^{\circ} \mathrm{C}$, Mixed with Surface Active Agent.

The surface active agent is added to the aqueous solution of PMA $(12 \mu \mathrm{g} / \mathrm{ml})$ in concentration of $24 \mu \mathrm{g} / \mathrm{ml}$. This component ratio of PMA and surface active agent is close to that of many mercuric wettable powders. The results are shown in Table II.

\section{RESULTS AND DISCUSSIONS}

1) The Influences of Carriers and Surface Active Agents on Decomposition of Blastcidin S.

None of the used carriers was unstable.
TABLE I. INFLUENCE OF SURFACTANTS AND GARRIERS ON THE STABILITY OF BLASTCIDIN S UNDER SEVERE CONDITION

Tested Sample

$\begin{array}{cc}\text { Clay } & \mathrm{A} \\ \text { / } & \mathrm{B} \\ \text { / } & \mathrm{C}\end{array}$

BcS-Potency

Kaolin A

"I B

II $\mathrm{C}$

Talc A

/l B

White carbon

Sodium lauryl sulfate $(40 \%)$

Sodium dodecylbenzene sulfate

Sodium methane dinaphthalenedisulfonate (A-A)

Sodium methane dinaphthalenedisulfonate (A-B)

(POE) isooctylphenylether (POE $8 \mathrm{~mol}$ )

(POE) nonylphenylether (POE $5 \mathrm{~mol}$ )

$\mathrm{N}-103$

Waste liquor of pulp product

Calcium ligninsulfate

$\begin{array}{rl}\begin{array}{r}9 \text { day } \\ 85 \%\end{array} & \begin{array}{l}22 \text { day } \\ 79\end{array} \\ 126 \% \\ 103 & 115 \\ 126 & 128 \\ 105 & 114 \\ 82 & 114 \\ 99 & 121 \\ 98 & 124 \\ 92 & 113 \\ 81 & 120 \\ 99 & 103 \\ 114 & 96 \\ & \\ 59 & 22 \\ 95 & 95 \\ 92 & 119 \\ 99 & 92 \\ 68 & 72 \\ 45 & 55\end{array}$

Table II. Decomposition Test of PMA in Water Solution, Mixed with Various SURFACE ACTIVE AGENTS

\begin{tabular}{|c|c|c|c|c|c|c|c|}
\hline \multirow{2}{*}{$\begin{array}{c}\text { Code } \\
\text { No. }\end{array}$} & \multicolumn{2}{|c|}{ Surface active agent } & \multirow[b]{2}{*}{$\mathrm{pH}$} & \multicolumn{2}{|r|}{3 days } & \multicolumn{2}{|r|}{6 days } \\
\hline & Sample & $\underset{\text { content }}{\mathrm{H}_{2} \mathrm{O}}$ & & $\mathrm{Hg} \%$ & $\begin{array}{l}\text { Decomposition } \\
\text { percentage }\end{array}$ & $\mathrm{Hg} \%$ & $\begin{array}{l}\text { Decomposition } \\
\text { percentage }\end{array}$ \\
\hline 1. & A-A & 8.8 & 9.0 & 58.84 & 0.9 & 58.43 & 1.6 \\
\hline 2. & A-A-As & 7.5 & 7.2 & 59.33 & 0.1 & 59.29 & 0.2 \\
\hline 3. & $\mathrm{~A}-\mathrm{A}-\mathrm{Ca}$ & 5.1 & 7.4 & 59.24 & 0.3 & 59.02 & 0.6 \\
\hline 4. & $A-B$ & 6.4 & 9.6 & 59.06 & 0.6 & 58.88 & 0.9 \\
\hline 5. & L-C & 11.2 & 6.5 & 48.82 & 17.8 & 48.10 & 21.9 \\
\hline 6. & $\mathrm{~L}-\mathrm{A}$ & 14.2 & 7.2 & 45.83 & 22.8 & 45.42 & 23.6 \\
\hline 7. & Sodium laurylsulfate & 3.2 & 6.8 & 58.66 & 1.2 & 58.70 & 1.2 \\
\hline 8. & $\begin{array}{l}\text { Waste liquor of pulp } \\
\text { product }\end{array}$ & 7.5 & 5.2 & 48.69 & 18.0 & 48.60 & 18.2 \\
\hline 9. & $\mathrm{~N}-103$ & $1 \%>$ & 5.6 & 59.21 & 0.4 & 59.20 & 0.4 \\
\hline 10. & POE nonylphenyl & $1 \%>$ & 5.0 & 59.24 & 0.3 & 59.24 & 0.3 \\
\hline 11. & Control & & & 59.06 & 0.6 & 58.70 & 1.2 \\
\hline & $\begin{array}{l}\text { 1. A-A-As Ammonium-methar } \\
\text { 2. A-A-Ca Calcium-methane } \\
\text { 3. A-A \& A-B were mentioned } \\
\text { 4. L-C \& L-A are ligninsulfate } \\
\text { 5. } \mathrm{H}_{2} \mathrm{O} \text { content were determir } \\
\text { 6. pH-values were determined }\end{array}$ & $\begin{array}{l}\text { dinaphthal } \\
\text { naphthalene } \\
\text { at Table I. } \\
\text { calcium and } \\
\text { d by metho } \\
\text { the case o }\end{array}$ & dis & $\begin{array}{l}\text { onate. } \\
\text { m salt. } \\
\text { Fisher o } \\
\text { er susper }\end{array}$ & llation. & & \\
\hline
\end{tabular}


The tested samples on 9th day and 22nd day had some differences. It must be the influence of bias in Bioassay.

On the other hand, there are many surface active agents which show severe degradation, i.e., some Tamol* type and ligninsulfate type used on both 9 th day and 22nd day. But, among Tamol types, the neutral products are more stable than the alkaline products. The degradation of lignin sulfate is due to the influence of contaminated sulfite salt.

From the above facts, it was found that the some tyeps of anionic surfactants exerted in. fluence on Blastcidin $S$.

\section{2) The Decomposition of PMA by Surface Active} Agents.

Lignin sulfate and waste liquor of pulp product gave the same influences to Blastcidin $S$ and PMA. This seems to be caused by the reducing substances which contaminate with them. But, in the case of Tamol type, the surface active agent of this type gave no influence to PMA. This means that PMA has a possibility to be converted to $\mathrm{PMF}^{* *}$ after reacted with the surface active agent of Tamol type.

From the results of 1) and 2), the desirable

* Condensed product of formaldehyde and Naphthalene sulfonic acid. ** Phenylmercuric Fixtant: Phenylmercuric-methanedinaphthalenedisulfonate. surface active substances for Blastcidin $\mathrm{S}$ and PMA are only the type of lauryl sulfate and soapless soap among anionic surfactants.

\section{SUMMARY}

For the purpose of finding out the effective fungicide against rice blast, Piricularia oryzae, the author studies on the formulation of Blastcidin S and PMA. It was found that alkaline surface active agent of Tamol type and lignin sulfate gave undesirable influences to Blastcidin S, while lignin sulfate and the waste liquor of pulp products exerted bad effect upon PMA. From these facts, it was difficult to use anionic surfactant in the formulation.

Acknowledgement. The author wishes to express his sincere thanks to Emeritus Prof. Y. Sumiki, University of Tokyo for his guidance throughout the course of this work and to Prof. M. Nakajima, University of Kyoto, and Prof. H. Yonehara, University of Tokyo for their kind directions. Thanks are also due to Mr. S. Sasaki and Mr. T. Akashiba, colleague of our Institute, for their valuable suggestions and cordial assistance. Acknowl. edgement is given to Mr. T. Kihara, Director of our Institute, for his encouragement in this work. 